\title{
Correlations Between Clinical Features and Mouth Opening in Patients With Systemic Sclerosis
}

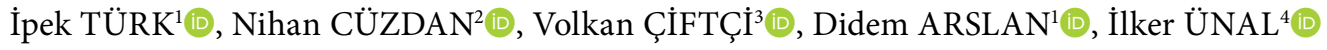 \\ ${ }^{1}$ Department of Internal Medicine, Division of Rheumatology, Çukurova University Faculty of Medicine, Adana, Turkey \\ ${ }^{2}$ Department of Physical Medicine and Rehabilitation, Division of Rheumatology, Çukurova University Faculty of Medicine, Adana, Turkey \\ ${ }^{3}$ Department of Pediatric Dentistry, Çukurova University Faculty of Dentistry, Adana, Turkey \\ ${ }^{4}$ Department of Biostatistics, Çukurova University Faculty of Medicine, Adana, Turkey
}

\begin{abstract}
Objectives: This study aims to investigate the correlations between clinical features and mouth opening in patients with systemic sclerosis (SSc). Patients and methods: Eighty patients with SSc (13 males, 67 females; mean age 53.4 \pm 11.7 years; range, 31 to 76 years) followed in our clinic were enrolled in the study. Skin involvement was assessed using the modified Rodnan skin score (mRSS), joint/tendon involvement with finger-tip to palm (FTP) distance and interstitial lung disease (ILD) was evaluated with clinical and radiologic methods. The interincisal distance (ID) measurement was used to assess the maximal mouth opening capacity. We examined associations between the ID and clinical features of SSc.

Results: The ID was lower in females compared with males, and in diffuse type compared with the limited type ( $<<0.001$ and $p<0.001$, respectively). A significant negative correlation was found between the ID with mRSS and FTP distance ( $p<0.001$ and $p=0.001$, respectively). The ID was lower in patients with ILD than in patients without ILD $(p=0.006)$. A formula was constituted to predict the maximal mouth opening of the patient with regression analysis. According to the formula, being male was associated with an increase of $6.14 \mathrm{~mm}$, the presence of ILD with a decrease of $3.19 \mathrm{~mm}$, every $10 \mathrm{~mm}$ increment in $\mathrm{mRSS}$ with a decrease of $3.72 \mathrm{~mm}$ and FTP distance $>0 \mathrm{~mm}$ with a decrease of $5.13 \mathrm{~mm}$ in mouth opening.

Conclusion: Microstomia is associated with low quality of life in patients with SSc. In our study, sex, ILD, mRSS, and FTP distance were observed to be the most important factors that were related with mouth opening in patients with SSc.

Keywords: Interincisal distance, microstomia, mouth opening, systemic sclerosis.
\end{abstract}

Systemic sclerosis (SSc) is a systemic disease of unknown origin of the connective tissue characterized by the fibrosis of skin and internal organs. Clinically, even though the most characteristic feature of SSc is skin fibrosis, inflammatory, fibrotic, and vascular changes may also be observed in the gastrointestinal (GI) system, kidneys, lungs and heart. Microstomia is seen in patients with $\mathrm{SSc}$ as a result of perioral soft tissue fibrosis. ${ }^{1}$ Gingival and dental health deteriorate in these patients and chewing problems can occur due to tooth loss, which eventually results in eating problems and malnutrition. ${ }^{2,3}$ Microstomia affects social interactions and the quality of life of patients unfavorably. ${ }^{1,4}$ Furthermore, the reduction in mouth opening may cause difficulties in procedures requiring anesthesia ${ }^{5}$ and compliance problems may occur in respiratory function tests, which have a major role in monitoring pulmonary involvement of the disease.

Received: February 19, 2019 Accepted: June 28, 2019 Published online: February 07, 2020

Correspondence: İpek Türk, MD. Çukurova Üniversitesi Tıp Fakültesi İç Hastalıkları Anabilim Dalı, Romatoloji Bilim Dalı, 01790 Balcalı, Adana, Turkey. Tel: +90 505 - 9487465 e-mail: sanlisoyturk@yahoo.com

Türk İ, Cüzdan N, Çiftçi V, Arslan D, Ünal İ. Correlations Between Clinical Features and Mouth Opening in Patients With Systemic Sclerosis. Arch Rheumatol 2020;35(2):196-204. 
Pizzo et al. ${ }^{6}$ found that a nonsurgical exercise program improved the mouth opening of patients with SSc. Maddali-Bongi et al. ${ }^{7}$ reported improvements in oral apertures of patients with $\mathrm{SSc}$ after a nine-week rehabilitation period. Based on these studies, early recognition of microstomia and planning exercise programs might be useful in the management of patients with SSc.

In a study in which the relationship between clinical features and orofacial manifestations of patients with SSc were investigated, mouth opening was found to be associated with the modified Rodnan skin score (mRSS), and type and severity of the disease. ${ }^{8}$ In this study, we aimed to investigate the correlations between clinical features and mouth opening in patients with SSc.

The aim of this study was to evaluate the ID of patients with SSc who were followed in our clinic and to investigate the factors affecting mouth opening.

\section{PATIENTS AND METHODS}

Eighty patients (13 males, 67 females; mean age $53.4 \pm 11.7$ years; range, 31 to 76 years) with diffuse and limited $\mathrm{SSc}$, diagnosed according to the American College of Rheumatology/ European League Against Rheumatism 2013 criteria, who presented to Çukurova University Faculty of Medicine, Rheumatology Department in- and outpatient clinics between July 2016 and February 2017 were included in this crosssectional study. ${ }^{9}$ Diffuse and limited separation was established on the basis of the extent of skin involvement. ${ }^{10}$ The exclusion criteria were as follows: age $<18$ years, history of maxillofacial trauma or oral malignancies, pregnancy, absence of central incisors and having orthodontic anomalies. Edentulous patients with dentures were enrolled in the study. The study protocol was approved by the Çukurova University Faculty of Medicine Ethics Committee (Date: 15.07.2016, Reference number 55/2). A written informed consent was obtained from each patient. The study was conducted in accordance with the principles of the Declaration of Helsinki.

Age, sex, smoking status, monthly income, education level, place of residence, and immunosuppressive medications were recorded.
The duration of disease was measured as the time between the onset of the first non-Raynaud's symptom and the study visit.

The severity of skin involvement was measured with the mRSS. ${ }^{11}$ The mRSS is a scoring method that evaluates skin thickness in 17 areas of the body and is rated using a 0-3 scale. The total score ranges between $0-51$. Tendon/joint involvement was evaluated with average finger-tip to palm (FTP) distance. ${ }^{8}$ The FTP distance is a method in which the distance from the tip of the third finger to the distal palmar crease is measured with the hand fully flexed. ${ }^{12}$ The average of the right and left hand measurements was taken. The presence of telangiectasia and calcinosis was noted. Telangiectasia is defined as dilated capillaries and venules that can be observed macroscopically. ${ }^{13}$ Patients were asked whether they had had digital ulcers (DUs) throughout the disease process. If present, the number of DUs in last year was recorded as $0,1-2$, and $\geq 3 .{ }^{14}$

Anti-nuclear antibody, anti-topoisomerase I (anti-scl-70), anti-centromere antibody, complete hemogram and biochemical tests were extracted from the hospital database.

Pulmonary involvement: presence of interstitial lung disease (ILD), forced vital capacity (FVC), diffusion capacity for carbon monoxide (DLCO), systolic pulmonary arterial pressure (PAP) value in Doppler echocardiography at the time of the study visit were extracted from the hospital database. In addition, if present, the average PAP value using right heart catheterization $(\mathrm{RHC})$ was recorded from the hospital database. Evidence of ILD on computed tomography, supported by a restrictive pattern on pulmonary function tests, was accepted as interstitial pulmonary disease. ${ }^{15}$ Pulmonary hypertension was considered when systolic PAP was estimated to be $>40 \mathrm{mmHg}$ by Doppler echocardiogram or when the mean PAP was found to be equal or higher than $25 \mathrm{mmHg}$ at rest in $\mathrm{RHC} .{ }^{16}$

Heart involvement: the presence of one of the following pathologies: pericarditis, ischemic cardiomyopathy of unknown origin, disturbance on color Doppler echocardiography, electrocardiographic anomaly that cannot be explained by another cause or left ventricular ejection fraction below 50\% is considered as cardiac involvement. ${ }^{16}$ 


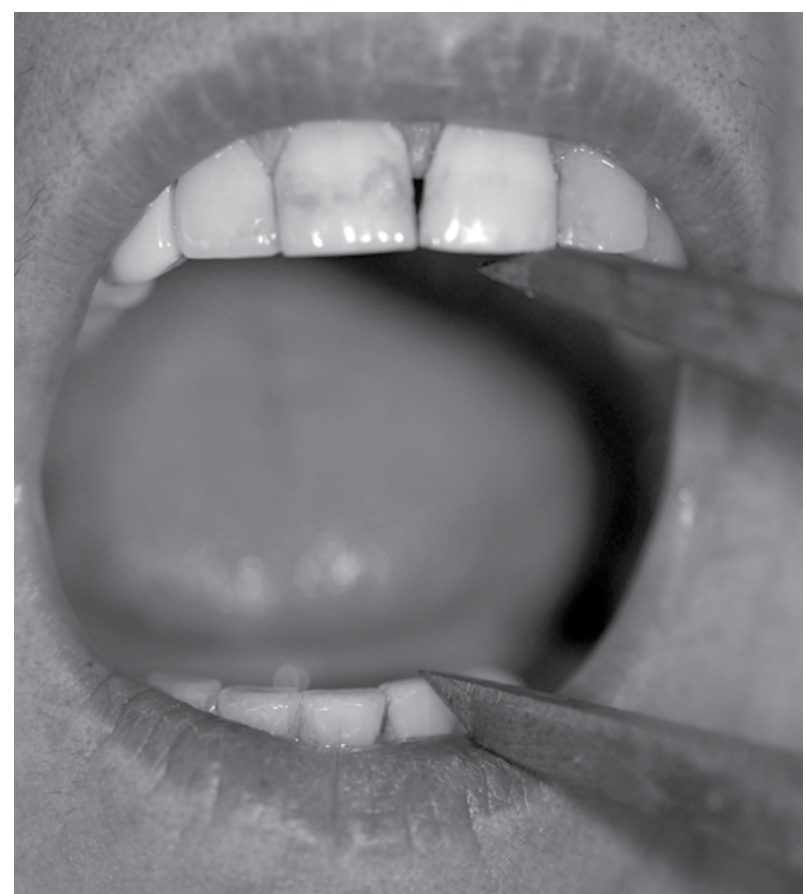

Figure 1. Interincisal distance measurement.

Gastrointestinal involvement: patients were questioned for dysphagia and gastroesophageal reflux as an indicator of esophageal involvement, early satiety, and vomiting as gastric involvement, and diarrhea, constipation and bloating as bowel involvement. ${ }^{17}$

The modified Medsger disease severity scale was used to assess nine organ systems: general health, peripheral vascular, skin, joint/tendon, muscle, GI tract, lungs, heart, and kidneys. Each organ system is scored from zero (no involvement) to four (severe involvement). ${ }^{18}$
Patients were referred to the Faculty of Dentistry for the interincisal distance (ID) measurement. An experienced dentist performed the dental examination of this study. The maximal mouth opening capacity (MOC) was measured using the ID between the maxillary and mandibular central incisors in the midline as described by Wood and Branco. ${ }^{19}$ Before measuring MOC, the subjects were asked to rest in the visiting area for at least 10 minutes. MOC was measured for each subject in the Frankfort horizontal plane (a line from the tragus of the ear through the palpable bony infraorbital rim area), which was oriented parallel to the floor, according to the natural head position in a dental unit. The subjects were asked to open their mouths as wide as they could with no pain. The linear distance from the incisal edge of the upper central incisor to the incisal edge of the lower central incisor was recorded using a dental bow compass and measured with a millimeter ruler. Each subject was measured three times every two minutes and the highest value of these three measurements was recorded (Figure 1). ${ }^{20}$

\section{Statistical analysis}

All analyses were performed using the IBM SPSS version 20.0 software (IBM Corp., Armonk, NY, USA). Categorical measurements were summarized as numbers and percentages, and numerical measurements were summarized as mean and standard deviation (median and minimum-maximum where appropriate). The chisquare test was used to compare categorical variables between the groups. The normality of distribution for continuous variables was confirmed using the Kolmogorov-Smirnov test. For the comparison of continuous variables between two

Table 1. Socio-demographic characteristics of patients with diffuse and limited systemic sclerosis

\begin{tabular}{|c|c|c|c|c|c|c|c|c|c|c|c|}
\hline & \multicolumn{5}{|c|}{ Diffuse SSc } & \multicolumn{5}{|c|}{ Limited SSc } & \multirow[b]{2}{*}{$p$} \\
\hline & $\mathrm{n}$ & $\%$ & Mean \pm SD & Median & Min-Max & $\mathrm{n}$ & $\%$ & Mean \pm SD & Median & Min-Max & \\
\hline Age (year) & & & $53.0 \pm 12.1$ & & & & & $54.4 \pm 10.8$ & & & 0.618 \\
\hline $\begin{array}{l}\text { Sex } \\
\text { Female }\end{array}$ & 50 & 90.9 & & & & 17 & 68 & & & & 0.019 \\
\hline Disease duration (month) & & & & 96 & $8-348$ & & & & 96 & $6-240$ & 0.791 \\
\hline Smoked ever & 7 & 12.7 & & & & 13 & 52 & & & & $<0.001$ \\
\hline $\begin{array}{l}\text { Place of residence } \\
\text { Urban }\end{array}$ & 40 & 72.7 & & & & 14 & 56 & & & & 0.139 \\
\hline
\end{tabular}


groups, Student's t-test or the Mann-Whitney U test was used depending on whether the statistical hypotheses were fulfilled. For comparisons of more than two groups, one-way analysis of variance was used. Regarding the homogeneity of variances, the Bonferroni, Scheffe, and Tamhane tests were used for multiple comparisons of groups. To evaluate the correlations between measurements, Pearson's correlation coefficient was used. Linear regression analysis was applied to determine the most effective predictors of ID. The regression model was constituted by variables in univariate analyses that had a $p$ value below 0.25 or variables above this level that were clinically significant. The statistical level of significance for all tests was considered as 0.05 .

\section{RESULTS}

Eighty patients with SSc, 55 with diffuse and 25 with limited SSc, were enrolled in the study.
Most of the patients (83.8\%) were female and the mean age was $53.4 \pm 11.7$ years. The sociodemographic characteristics of all patients are summarized in Table 1, and a comparison of clinical and laboratory characteristics of patients with diffuse and limited SSc is summarized in Table 2.

The ID was statistically significantly lower in females compared with males $(35.5 \pm 7.0 \mathrm{~mm}$ and $43.2 \pm 5.6 \mathrm{~mm}$, respectively, $\mathrm{p}<0.001$ ), and in diffuse type compared with the limited type $(34.1 \pm 6.7 \mathrm{~mm}$ and $42.5 \pm 4.9 \mathrm{~mm}$, respectively, $\mathrm{p}<0.001$ ). No significant relationship was observed between ID and disease duration, monthly income, age, and level of education ( $p>0.05$ ). A significantly weak positive correlation was detected between mouth opening and height ( $p=0.005, r=0.312$ ).

As the mRSS increased, the ID decreased $(p<0.001, r=-0.608)$. A statistically significant negative correlation was found between the

Table 2. Comparison of clinical and laboratory characteristics of patients with diffuse and limited systemic sclerosis

\begin{tabular}{|c|c|c|c|c|c|c|c|}
\hline & \multicolumn{3}{|c|}{ Diffuse type } & \multicolumn{3}{|c|}{ Limited type } & \multirow[b]{2}{*}{$p$} \\
\hline & $\mathrm{n}$ & $\%$ & Mean \pm SD & $\mathrm{n}$ & $\%$ & Mean \pm SD & \\
\hline Presence of calcinosis & 20 & 37 & & 3 & 12 & & 0.023 \\
\hline Presence of telangiectasia & 45 & 83.3 & & 17 & 68 & & 0.123 \\
\hline mRSS & & & $20.3 \pm 8.5$ & & & $12.1 \pm 7.7$ & $<0.001$ \\
\hline $\mathrm{FTP}>0$ & 19 & 35.8 & & 1 & 4 & & 0.003 \\
\hline Presence of ILD & 53 & 96.4 & & 14 & 56 & & $<0.001$ \\
\hline Cardiac involvement & 9 & 16.4 & & 1 & 4 & & 0.160 \\
\hline GERD & 33 & 60 & & 13 & 52 & & 0.502 \\
\hline History of DU & 37 & 67.3 & & 16 & 64 & & 0.774 \\
\hline $\begin{array}{l}\text { DU count in the previous year } \\
0 \\
\geq 3\end{array}$ & $\begin{array}{l}25 \\
18\end{array}$ & $\begin{array}{l}45.5 \\
32.7\end{array}$ & & $\begin{array}{c}10 \\
7\end{array}$ & $\begin{array}{l}40 \\
28\end{array}$ & & 0.621 \\
\hline Patients receiving immunosuppressive treatment & 50 & 90.9 & & 14 & 56 & & $<0.001$ \\
\hline FVC predicted & & & $71.3 \pm 16.8$ & & & $103.8 \pm 26.7$ & $<0.001$ \\
\hline DLCO predicted & & & $47.6 \pm 17.6$ & & & $72.3 \pm 21.4$ & $<0.001$ \\
\hline \multicolumn{8}{|l|}{ Auto antibodies } \\
\hline ANA & 53 & 98.1 & & 21 & 87.5 & & 0.087 \\
\hline Anti-scl-70 & 51 & 95.7 & & 2 & 4.3 & & $<0.001$ \\
\hline Anti-centromere antibody & 1 & 2 & & 12 & 52.2 & & $<0.001$ \\
\hline Albumin (g/dL) & & & $3.5 \pm 0.4$ & & & $3.9 \pm 0.5$ & 0.001 \\
\hline
\end{tabular}

SD: Standard deviation; mRSS: Modified Rodnan skin score; FTP >0: Finger-tip to palm distance greater than 0; ILD: Interstitial lung disease; GERD: Gastroesophageal reflux disease; DU: Digital ulcer; FVC: Forced vital capacity; DLCO: Diffusing capacity for carbon monoxide; ANA: Anti-nuclear antibody; Anti-scl-70: anti-topoisomerase I. 
Table 3. Univariate associations between Medsger groups regarding interincisal distance

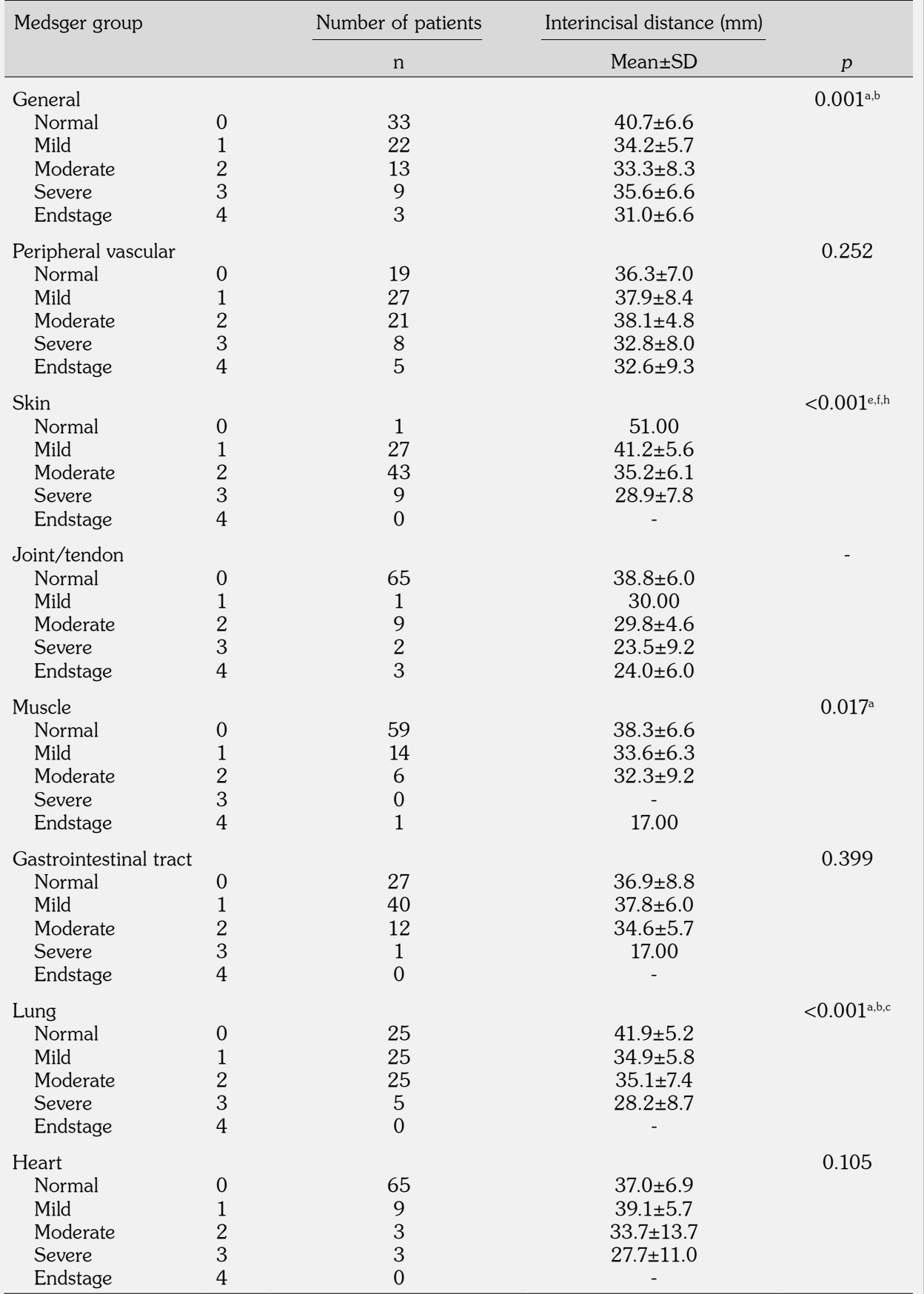

SD: Standard deviation; a: $p<0.05$ for Medsger group normal vs. mild; b: $p<0.05$ for Medsger group normal vs. moderate; $\mathrm{c} p<0.05$ for Medsger group normal vs. severe; $d: p<0.05$ for Medsger group normal vs. endstage; e: $p<0.05$ for Medsger group mild vs. moderate; f: $p<0.05$ for Medsger group mild vs. severe; $\mathrm{g}$ : $\mathrm{p}<0.05$ for Medsger group mild vs. endstage; $\mathrm{h}: \mathrm{p}<0.05$ for Medsger group modarate vs. severe; $1: \mathrm{p}<0.05$ for Medsger group moderate vs. endstage.

Maximal mounth opening $=49.46+(6.146 \times$ Being male $)-(3.195 \times$ ILD $)-(0.372 \times$ mRSS $)-\left(5.139 \times\right.$ FTP $\left.^{*}\right)$

Coefficients were adjusted according to age (Adjusted $\mathrm{R}^{2}=0.581$ )

ILD: Interstitial lung disease; mRSS: Modified Rodnan skin score; FTP: Finger-tip to palm distance; ${ }^{*}$ Finger-tip to palm distance $>0$ mm

According to the formula: Value for male sex is given 1 , female sex is 0 ; value for presence of ILD is given 1 , if not 0 ; value for FTP $>0$ mm is 1 , FTP=0 mm is 0 .

Figure 2. Formula constituted to predict maximal mouth opening. 
ID and FTP distance $(p=0.001, r=-0.680)$. ID was significantly lower in patients with FTP distance $>0 \mathrm{~mm}$ compared with those with $0 \mathrm{~mm}$ $(30.9 \pm 7.3 \mathrm{~mm}$ and $38.9 \pm 6.3 \mathrm{~mm}$, respectively, $p<0.001)$. ID was observed to be lower in the patient group with telangiectasia compared with the patient group without telangiectasia $(35.9 \pm 6.9 \mathrm{~mm}$ and $40.6 \pm 7.5 \mathrm{~mm}$, respectively, $\mathrm{p}=0.017)$. ID was lower in the patient group with calcinosis compared with the group in which calcinosis was absent $(33.1 \pm 7.8 \mathrm{~mm}$ and $38.4 \pm 6.5 \mathrm{~mm}$, respectively, $\mathrm{p}=0.003$ ). No significant relationship was observed between the ID and the history of DU or DU number in the last year ( $p=0.542$ and $p=0.311$, respectively).

The ID was lower in the group with positive anti-scl-70 ( $p=0.007)$ antibodies and higher in the group with positive anti-centromere antibodies $(p=0.020)$. The ID was lower in patients with ILD than in patients without ILD $(35.8 \pm 7.5 \mathrm{~mm}$ and $41.8 \pm 3.6 \mathrm{~mm}$, respectively, $\mathrm{p}=0.006)$. A significantly weak positive correlation was seen between ID and FVC $(p<0.001, r=0.408)$ and a significantly weak positive correlation was found between ID and DLCO ( $p=0.004, r=0.342)$. No significant relationship was observed between ID and pulmonary hypertension $(p=0.351)$.

The ID was lower in the patient group with cardiac involvement compared with the patient group without cardiac involvement $(32.3 \pm 8.8 \mathrm{~mm}$ and $37.4 \pm 6.9 \mathrm{~mm}$, respectively, $p=0.038$ ). No significant relationship was detected between GI system involvement and mouth opening $(\mathrm{p}=0.850)$.

When the patients were grouped according to their Medsger general scores (0-4), there was a statistically significant difference between the groups regarding the ID $(p=0.001)$. According

Table 4. Factors most affecting interincisal distance with regression analysis

\begin{tabular}{lcc}
\hline & $p$ & Beta \\
\hline Being male & $<0.001$ & 6.146 \\
Presence of ILD & 0.037 & -3.195 \\
mRSS & $<0.001$ & -0.372 \\
FTP $>0$ mm & $<0.001$ & -5.139 \\
\hline ILD: Interstitial lung disease; mRSS: & Modified Rodnan skin score; \\
FTP $>0$ : Finger tip to palm distance greater than 0.
\end{tabular}

to the multiple comparison tests, the abovementioned difference was shown to originate from the groups with Medsger general scores of 0-1 and $0-2(p=0.023$ and $p=0.034$, respectively) (Table 3).

When patients were grouped according to their Medsger peripheral vascular scores, no significant difference was observed between the groups regarding ID ( $p=0.252)$.

There was a significant difference between Medsger skin score groups regarding ID ( $p<0.001)$. ID was reduced from 1 to 3 in skin scores. A significant difference was observed between the groups with Medsger skin scores of 1-2, 1-3, and $2-3$ regarding the ID $(p=0.001, p<0.001$, and $p=0.024$, respectively).

When the patients were grouped according to their Medsger muscle scores, there was a significant difference between groups regarding the ID $(p=0.017)$. Mouth opening tended to reduce from group 0 to 2 . ID was significantly higher in the group with a score of 0 compared with those who scored $1(p=0.049)$.

No significant differences were observed between Medsger GI tract subtype groups $(p=0.399)$. With regard to ID, a significant difference was observed between Medsger lung score groups $(p<0.001)$. A significant difference was observed between groups with Medsger lung scores of $0-1,0-2$ and $0-3(p=0.003, p=0.004$, and $\mathrm{p}=0.001$, respectively).

Factors affecting ID were evaluated with linear regression analysis. Sex, disease type, mRSS, FTP distance, telangiectasia, calcinosis, ILD, cardiac involvement, and Medsger scores were included in the regression analysis. According to the stepwise procedure, sex, presence of ILD, FTP distance $>0 \mathrm{~mm}$ and mRSS were found to be the most effective factors on mouth opening (Figure 2, Table 4). Coefficients were adjusted according to age. A formula was constituted to predict the maximal mouth opening of the patients. According to the formula, being male was associated with an increase of $6.14 \mathrm{~mm}$, the presence of ILD with a decrease of $3.19 \mathrm{~mm}$, every $10 \mathrm{~mm}$ increment in mRSS with a decrease of $3.72 \mathrm{~mm}$, and FTP distance $>0 \mathrm{~mm}$ with a decrease of $5.13 \mathrm{~mm}$ in mouth opening. 


\section{DISCUSSION}

In our study, ID was found to be lower in females compared with male patients. Studies comparing mouth opening between the sexes have mostly been conducted in healthy populations, and mouth opening has been measured lower in females. ${ }^{5,21}$ In a study by Baron et al., ${ }^{8}$ which was performed in patients with SSc, no difference was observed between male and female patients regarding mouth opening. The lower measurements of oral aperture in healthy females and the positive correlation with height may be the reasons of microstomia in female patients with SSc. ${ }^{22}$

According to the results of our study, the extent and severity of skin involvement measured using the mRSS was found to be a substantial factor that affected mouth opening. Formerly, perioral fibrosis was reported to be one of the most significant causes of microstomia. ${ }^{1}$ Depending on the severity of perioral fibrosis, it can be predicted that skin involvement in the facial region may directly affect mouth opening. It is not surprising to find a strong association between the mRSS and mouth opening considering that facial involvement is one of the subcomponents of the mRSS, indicating disease activity in addition to skin involvement severity. In addition, an association was found between mouth opening and the presence of telangiectasia and calcinosis in our study. In the study of Zhang et al., ${ }^{13}$ it was observed that facial sclerosis and finger/toe sclerosis were more common in patients with telangiectasia. On the basis of these two studies, it may be considered that relatively reduced mouth opening in patients with telangiectasia might be due to the higher incidence of face sclerosis. Even though calcinosis has been reported to be observed mostly in limited SSc, ${ }^{23,24}$ in our study, similar to a study conducted by Cruz-Domínguez et al., ${ }^{25}$ calcinosis was observed more frequently in diffuse type SSc. Furthermore, in the same study, it was reported that Medsger skin scores and joint/tendon scores were higher in the group with calcinosis. Despite being a direct determinant, calcinosis may be regarded as one of the factors that affects mouth opening due to the higher incidence in the diffuse type of the disease, and its strong relationship with skin scores.

Finger-tip to palm distance is accepted as an indicator of tendon and joint involvement in patients with SSc. ${ }^{26}$ In our study, a significant negative correlation was observed between FTP distance values and mouth opening. Fingertip to palm distance has been found to be related with the severity of skin involvement in a previous study. ${ }^{27}$ Furthermore, the presence of temporomandibular joint (TMJ) involvement and involvement of perioral muscle tendons in patients with SSc might increase the clinical value of the FTP distance measurement. ${ }^{1}$ In a study conducted by Matarese et al., ${ }^{28}$ clinical and magnetic resonance imaging findings related to TMJ dysfunction were found to be higher compared with control groups in patients with SSc. Accordingly, it can be claimed that the severity of tendon and joint involvement around the oral region is at least as important as the degree of skin involvement.

No significant relationship was observed between mouth opening and parameters of digital ulcer. Although vasculopathy is the main problem leading to digital ulcers, the basic cause leading to microstomia is fibrosis. ${ }^{16}$ Depending on the different pathophysiologic mechanisms, the use of digital ulcer counts to predict mouth opening might be restricted.

In our study, associations were observed in all parameters indicating severity of lung involvement and mouth opening. Similar to our study, a significant relationship between the degree of lung involvement and mouth opening was observed in a study by Baron et al. ${ }^{8}$ Fibrosis plays a major role in the pathogenesis of ILD in SSc. ${ }^{29,30}$ There are publications showing that pulmonary fibrosis and skin fibrosis are related. ${ }^{31,32}$ Lung involvement, being a predictor of microstomia, may be due to sharing a common pathogenesis. Additionally, the fact that patients with ILD are more likely to have diffuse type SSc with an active course may be considered a factor in lung involvement being a determinant.

In our study, ID tended to reduce as disease activity increased in the general score, skin score, muscle score and lung score subunits of the Medsger activity index. However, according to the results of the multivariate analysis, the effect of disease activity on mouth opening was relatively restricted when compared with other parameters. In contrast to our study, in a study by Baron et al., ${ }^{8}$ no relationship was observed between mouth opening and general scores in a univariate analysis. 
In our study, patients were divided into five groups according to their Medsger general scores and the relationship between these groups regarding the mouth opening was examined. Different results might have been achieved because different statistical methods were used.

Our study has some limitations. We performed a cross-sectional study in a single center. Furthermore, the number of male patients was low. Therefore, the results cannot be generalized to the entire SSc population. Additionally, interand intra-reader variability was not assessed in the study. On the other hand, the strong points of our study are as follows: first, to our knowledge, this is the first study to investigate the associations of mouth opening with extensive clinical features and constitute a formula to predict the amount of microstomia of patients with SSc. Secondly, all ID measurements of the patients were performed by a single dentist to avoid bias.

In conclusion, according to our study, sex, lung involvement, mRSS and FTP distance measurements are the most important factors that affect mouth opening in patients with SSc. Based on our results, we assume that planning treatment options might be possible with early recognition of microstomia.

\section{Declaration of conflicting interests}

The authors declared no conflicts of interest with respect to the authorship and/or publication of this article.

\section{Funding}

The authors received no financial support for the research and/or authorship of this article.

\section{REFERENCES}

1. Crincoli V, Fatone L, Fanelli M, Rotolo RP, Chialà A, Favia G, et al. Orofacial Manifestations and Temporomandibular Disorders of Systemic Scleroderma: An Observational Study. Int J Mol Sci 2016;17.

2. Poole J, Conte C, Brewer C, Good CC, Perella $\mathrm{D}$, Rossie $\mathrm{KM}$, et al. Oral hygiene in scleroderma: The effectiveness of a multi-disciplinary intervention program. Disabil Rehabil 2010;32:379-84.

3. Baron M, Hudson M, Steele R. Malnutrition is common in systemic sclerosis: results from the Canadian scleroderma research group database. J Rheumatol 2009;36:2737-43.
4. Amin K, Clarke A, Sivakumar B, Puri A, Fox $\mathrm{Z}$, Brough $\mathrm{V}$, et al. The psychological impact of facial changes in scleroderma. Psychol Health Med 2011;16:304-12.

5. Gallagher C, Gallagher V, Whelton H, Cronin M. The normal range of mouth opening in an Irish population. J Oral Rehabil 2004;31:110-6.

6. Pizzo G, Scardina GA, Messina P. Effects of a nonsurgical exercise program on the decreased mouth opening in patients with systemic scleroderma. Clin Oral Investig 2003;7:175-8.

7. Maddali Bongi S, Del Rosso A, Galluccio F, Tai G, Sigismondi F, Passalacqua M, et al. Efficacy of a tailored rehabilitation program for systemic sclerosis. Clin Exp Rheumatol 2009;27:44-50.

8. Baron M, Hudson M, Tatibouet S, Steele R, Lo E, Gravel $\mathrm{S}$, et al. Relationship between disease characteristics and orofacial manifestations in systemic sclerosis: Canadian Systemic Sclerosis Oral Health Study III. Arthritis Care Res (Hoboken) 2015;67:681-90.

9. van den Hoogen F, Khanna D, Fransen J, Johnson SR, Baron M, Tyndall A, et al. 2013 classification criteria for systemic sclerosis: an American college of rheumatology/European league against rheumatism collaborative initiative. Ann Rheum Dis 2013;72:1747-55.

10. LeRoy EC, Medsger TA Jr. Criteria for the classification of early systemic sclerosis. J Rheumatol 2001;28:1573-6.

11. Furst DE, Clements PJ, Steen VD, Medsger TA Jr, Masi AT, D'Angelo WA, et al. The modified Rodnan skin score is an accurate reflection of skin biopsy thickness in systemic sclerosis. J Rheumatol 1998;25:84-8.

12. Torok KS, Baker NA, Lucas M, Domsic RT, Boudreau $\mathrm{R}$, Medsger TA Jr. Reliability and validity of the delta finger-to-palm (FTP), a new measure of finger range of motion in systemic sclerosis. Clin Exp Rheumatol 2010;28:28-36.

13. Zhang SZ, Xu D, Li MT, Hou Y, Wang Q, Tian Z, et al. Telangiectasia as a potential clinical marker of microvascular lesions in systemic sclerosis patients from EUSTAR data in China. Clin Exp Rheumatol 2015;33:106-10.

14. Guillevin L, Hunsche E, Denton CP, Krieg T, Schwierin B, Rosenberg D, et al. Functional impairment of systemic scleroderma patients with digital ulcerations: results from the DUO Registry. Clin Exp Rheumatol 2013;31:71-80.

15. Bartoli F, Fiori G, Braschi F, Amanzi L, Bruni C, Blagojevic $\mathrm{J}$, et al. Calcinosis in systemic sclerosis: subsets, distribution and complications. Rheumatology (Oxford) 2016;55:1610-4.

16. Tolosa-Vilella C, Morera-Morales ML, SimeónAznar CP, Marí-Alfonso B, Colunga-Arguelles D, Callejas Rubio JL, et al. Digital ulcers and cutaneous subsets of systemic sclerosis: Clinical, immunological, nailfold capillaroscopy, and survival differences in the 
Spanish RESCLE Registry. Semin Arthritis Rheum 2016;46:200-8.

17. Walker UA, Tyndall A, Czirják L, Denton C, FargeBancel D, Kowal-Bielecka O, et al. Clinical risk assessment of organ manifestations in systemic sclerosis: a report from the EULAR Scleroderma Trials And Research group database. Ann Rheum Dis 2007;66:754-63.

18. Medsger TA Jr, Bombardieri S, Czirjak L, Scorza R, Della Rossa A, Bencivelli W. Assessment of disease severity and prognosis. Clin Exp Rheumatol 2003;21:42-6.

19. Wood GD, Branco JA. A comparison of three methods of measuring maximal opening of the mouth. J Oral Surg 1979;37:175-7.

20. Yao KT, Lin CC, Hung $\mathrm{CH}$. Maximum mouth opening of ethnic. Chinese in Taiwan. J Dent Sci 2009;4:40-4.

21. Khare N, Patil SB, Kale SM, Sumeet J, Sonali I, Sumeet B. Normal mouth opening in an adult Indian population. J Maxillofac Oral Surg 2012;11:309-13.

22. Mezitis M, Rallis G, Zachariades N. The normal range of mouth opening. $\mathrm{J}$ Oral Maxillofac Surg 1989;47:1028-9.

23. Vayssairat M, Hidouche D, Abdoucheli-Baudot N, Gaitz JP. Clinical significance of subcutaneous calcinosis in patients with systemic sclerosis. Does diltiazem induce its regression? Ann Rheum Dis 1998;57:252-4

24. Boulman N, Slobodin G, Rozenbaum M, Rosner I. Calcinosis in rheumatic diseases. Semin Arthritis Rheum 2005;34:805-12.

25. Cruz-Domínguez MP, García-Collinot G, Saavedra MA, Medina G, Carranza-Muleiro RA, Vera-Lastra OL, et al. Clinical, biochemical, and radiological characterization of the calcinosis in a cohort of Mexican patients with systemic sclerosis. Clin Rheumatol 2017;36:111-7.

26. Clements PJ, Furst DE, Wong WK, Mayes M, White $\mathrm{B}$, Wigley $\mathrm{F}$, et al. High-dose versus lowdose D-penicillamine in early diffuse systemic sclerosis: analysis of a two-year, double-blind, randomized, controlled clinical trial. Arthritis Rheum 1999;42:1194-203.

27. Arslan Tas D, Erken E, Sakalli H, Yucel AE. Evaluating hand in systemic sclerosis. Rheumatol Int 2012;32:3581-6.

28. Matarese G, Isola G, Alibrandi A, Lo Gullo A, Bagnato G, Cordasco G, et al. Occlusal and MRI characterizations in systemic sclerosis patients: A prospective study from Southern Italian cohort. Joint Bone Spine 2016;83:57-62.

29. Schneider F, Gruden J, Tazelaar HD, Leslie KO. Pleuropulmonary pathology in patients with rheumatic disease. Arch Pathol Lab Med 2012;136:1242-52.

30. Sandmeier B, Jäger VK, Nagy G, Carreira PE, Tzankov A, Widuchowska M, et al. Autopsy versus clinical findings in patients with systemic sclerosis in a case series from patients of the EUSTAR database. Clin Exp Rheumatol 2015;33:75-9.

31. Lei L, Zhao C, Qin F, He ZY, Wang X, Zhong XN. Th17 cells and IL-17 promote the skin and lung inflammation and fibrosis process in a bleomycininduced murine model of systemic sclerosis. Clin Exp Rheumatol. 2016;34:14-22.

32. Lei L, Zhao C, Qin F, He ZY, Wang X, Zhong XN. Th17 cells and IL-17 promote the skin and lung inflammation and fibrosis process in a bleomycininduced murine model of systemic sclerosis. Clin Exp Rheumatol 2016;34:14-22. 